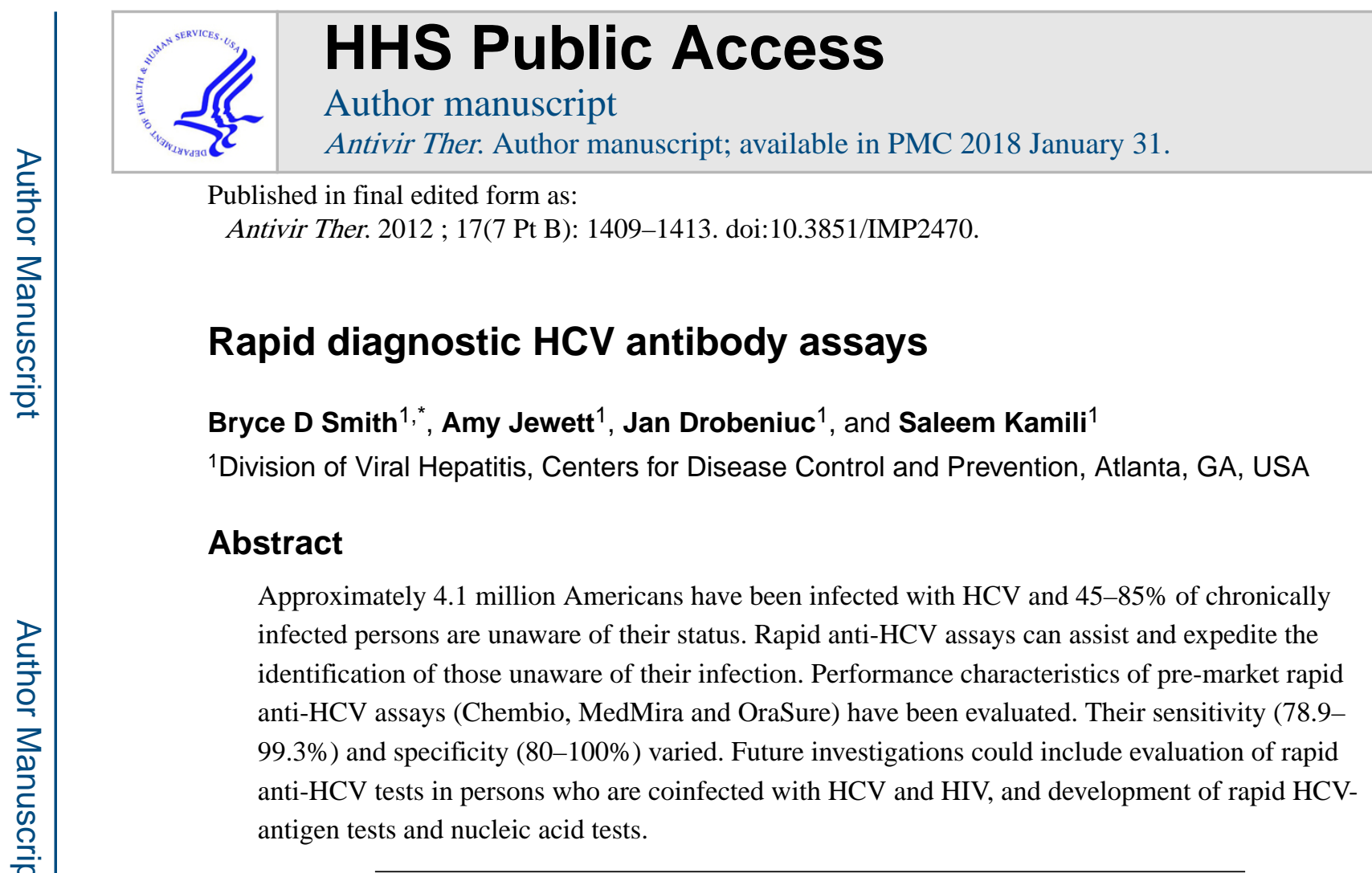

\title{
Introduction
}

The Centers for Disease Control and Prevention (CDC) estimates that 4.1 million Americans have been infected with HCV, 75-80\% of whom are living with chronic HCV infection [1]. $\mathrm{CDC}$ recommends routine $\mathrm{HCV}$ antibody (anti-HCV immunoglobulin $\mathrm{G}$ ) testing for persons at risk of infection [2]. Yet studies estimate that $45-85 \%$ of HCV-infected persons are unaware of their status [3-5]. Knowledge of HCV infection status is necessary for persons to make health promoting behaviour changes and treatment decisions.

Persons who inject drugs (PWID) account for 58\% of all anti-HCV-positive persons in the US [1] and CDC estimates that injection drug use (IDU) accounted for $56 \%$ of acute hepatitis $\mathrm{C}$ cases in the US in 2009 [6]. The estimated HCV prevalence among PWID ranges from $30 \%$ to $70 \%$, depending on frequency and duration of use $[7,8]$, and the incidence ranges from $16 \%$ to $42 \%$ per year $[9,10]$. Younger PWID ( $<30$ years old) have lower prevalence rates, ranging between $10 \%$ and $36 \%$, but this still translates to $>1 / 3$ of young PWID becoming infected [11,12]. At least $50 \%$ of persons who have a documented risk factor for HCV infection [2] do not receive anti-HCV testing [3,4]. Not only are PWID at increased risk for hepatitis $\mathrm{C}$, but they are also at risk for infection by HIV [13]. The prevalence of HIV infection among PWID is 6.2\% [14] and CDC recommends HCV screening of all HIV-infected individuals [15]. The prevalence of anti-HCV immunoglobulin $\mathrm{G}$ among persons infected with HIV is $24 \%$ and increases to $81 \%$ when the risk factor identified is IDU [13].

"Corresponding author: bli1@cdc.gov.

Disclosure statement

The authors declare no competing interests. The findings and conclusions in this report are those of the authors and do not necessarily represent the official position of the Centers for Disease Control and Prevention. 
Although PWIDs are at high risk for blood-borne infections such as HCV and HIV, they have limited access to health care [16]. Currently, PWID are tested infrequently for anti$\mathrm{HCV}$ immunoglobulin $\mathrm{G}$ and many of those who do test positive do not receive treatment because of comorbidities or contraindications, ongoing drug use, or reluctance by their physicians to treat. Additionally, many PWID who are tested for HCV using conventional assays do not return to receive their results. Point-of-care, rapid HCV testing enables the delivery of results at the time of testing [17]. PWID who receive rapid HIV tests have been shown to be more likely to be informed of their results than those tested with conventional assays, who must return at a later date [18].

Here, we summarize the outcomes of six studies [17,19-23] conducted in the US that examined the performance characteristics of rapid anti-HCV tests and propose a research agenda to support their adoption in the field.

\section{Evaluation strategy}

The six studies use lateral-flow immuno-chromatographic assay devices for testing serum, fingerstick blood and oral fluid, and originate from three manufacturers (Chembio [Medford, NY, USA], MedMira [Halifax, NS, Canada] and OraSure [Bethlehem, PA, USA]). Rapid test performance was evaluated using a standard algorithm recommended by CDC [24]. Discordant results were either tested for active $\mathrm{HCV}$ infection or for association with biological factors such as HIV status, age, sex and race/ethnicity. Active HCV infection was determined by quantitative nucleic acid testing (NAT) which detects the presence of the HCV RNA.

\section{Rapid assays}

Resource constraints, site-specific issues, and specimen type limited the ability to analyse each specimen fully, resulting in different sample sizes. The Chembio assay was evaluated in three studies using serum [22], fingerstick blood [17,23] and oral fluid [17,23] from PWID $(n=2,357)$. The MedMira assay was evaluated in three studies using serum [22] and fingerstick blood [23] from PWID $(n=1,940)$. The OraSure assay was evaluated in five studies, using serum [20-22], fingerstick blood [20,21,23] and oral fluid [19-21,23] from PWID, [17,19,22,23] low-risk individuals [21], and those with signs or symptoms of hepatitis $\mathrm{C}$ infection $[20](n=5,058)$.

\section{Reference assays}

All of the studies employed the CDC testing algorithm as reference for evaluation of test performance. The CDC algorithm uses previously established signal-to-cutoff (s/co) ratios unique to each immunoassay to determine the true anti-HCV status. Positivity is defined by either reactivity by the conventional enzyme immunoassay (EIA) being above an established s/co threshold or reactivity in recombinant immunoblot (RIBA) confirmatory test. Negativity is defined by either nonreactivity or negativity by RIBA. Three of the studies also included comparison to algorithms specific to the respective manufacturer's inserts [17,22,23]. Additionally, one of the sites in the field study [23] did not utilize the CDC algorithm and therefore the reported results were based upon comparison with the conventional EIA only. 


\section{Sensitivity and specificity}

Across all studies, sensitivity was defined as the number of positive specimens detected by the rapid assay divided by the total number of positive specimens as per the CDC testing algorithm. Specificity was defined as the number of negative specimens identified by the rapid assay divided by the total number of negative specimens as per the CDC algorithm.

\section{Results}

Overall, sensitivity and specificity was highest when using serum specimens as compared to fingerstick blood and oral fluid specimens. The sensitivity of the OraSure assay was higher than that of Chembio or MedMira (Table 1).

False-negative and false-positive results occurred with all assays and specimen types. The MedMira assay yielded the largest proportion of false-negative results (ranging from $8 \%$ to $19 \%)$ as compared to the Chembio $(0.4-7 \%)$ and OraSure (0-6\%) assays. In two studies, false-negative results were associated with HIV-positivity. In the laboratory setting the Chembio assay (adjusted [a]OR 11.0; 95\% CI 2.5, 48.2) and the MedMira assay (aOR 4.0; $95 \%$ CI 1.5, 10.2) were more likely to provide false-negative results if the specimens were also HIV-positive. In one field setting, the Chembio oral assay (aOR 9.1; 95\% CI 2.1, 39.3) was more likely to produce false-negative results if the specimens were also HIV-positive.

\section{Discussion}

The sensitivity and specificity of rapid anti-HCV assays varied across the six studies. Using serum specimens resulted in increased sensitivity as compared with fingerstick blood or oral fluid specimens. The OraSure assay had a higher sensitivity than the other 2 assays. In one study, the OraSure assay outperformed the conventional EIA [19]. Of 10 specimens with discordant results, 5 of 6 specimens that were OraSure-negative and EIA-positive had no detectable HCV RNA, and 2 specimens that were OraSure-positive and EIA-negative were HCV-RNA-positive. Results from the OraSure test seemed more concordant with NAT than from EIA. Whereas rapid assays provide information about anti-HCV immunoglobulin $\mathrm{G}$ which is a marker of active as well as resolved infection, NATs provide direct evidence of active $\mathrm{HCV}$ infection. This is an important distinction because between $15 \%$ and $33 \%$ of patients spontaneously clear the virus [25] resulting in an antibody-positive/NAT-negative result. Furthermore, HCV-infected patients who achieve sustained virological response after antiviral therapy will also demonstrate the same antibody-positive/NAT-negative profile.

False anti-HCV results occurred for all assays in all settings, but false results were not significantly associated with the selected demographic variables studied (HIV status, age, race/ethnicity or sex). For example, in one study, false-negative results were more likely to occur among females when using the MedMira assay [17]. In contrast, female sex was not associated with false results for any other assay or evaluation.

False anti-HCV-negative results from the Chembio and MedMira assays occurred more often when the specimen was from persons coinfected with HIV, similar to the findings of other studies using other assays [26-28]. Of the 43 HIV-positive specimens in one study, 60\% 
were anti-HCV-positive; HIV-positive specimens were between four and eleven times more likely to produce a false-negative rapid assay result [22]. This issue is of particular concern because the prevalence of HCV infection among HIV-positive persons is high $(24 \%)$ and, conversely, $81 \%$ of HIV-positive persons with a history of IDU are anti-HCV-positive [13]. HIV-HCV-coinfected persons are at a greater risk of progressing to an AIDS-defining event or death than those who are HIV monoinfected [29], and progress to end-stage liver disease in less than half the time of HCV-monoinfected persons [30,31].

In one study [23], field staff reported on implications of implementing rapid HCV testing in their settings. They reported that rapid testing for anti-HCV overcomes barriers to receiving referrals for NAT, medical care and other services. Prior to the study, field staff expressed concern that the time required for HCV testing would impede the HIV testing process. While they reported that rapid anti-HCV testing was time consuming, they also reported that it did not have a negative impact on HIV testing. However, staff reported a need for standardized educational materials and counselling messages. Demonstration studies are being conducted to evaluate the implementation of rapid anti-HCV assays, new educational materials, and counselling messages into HIV testing settings to better understand the impact of introducing a new test in an existing setting and how this may influence site operations. Further evaluation is required to understand the impact of rapid anti-HCV testing in other settings, such as emergency departments and primary care clinics with limited access to laboratories.

The OraSure rapid anti-HCV test, recently approved by FDA, enables testing in settings where $\mathrm{HCV}$ testing has previously been limited. Rapid assays are useful for increasing testing opportunities and address the public health problem of under-diagnosis of HCV infection. Other benefits include patients being able to receive test results and prevention counselling messages during the same visit, and that they can receive expedited referral for follow-up testing and care.

In contrast to conventional assays, rapid assays enable specimens (for example, fingerstick blood or oral fluid) to be collected and tested at the point-of-care and do not require a follow-up visit to receive test results. Of persons who consented to an HIV rapid test, 99\% received their results and prevention counselling and $>94 \%$ went to their first clinic appointment $[26,32,33]$. Since rapid HIV testing improves receipt of HIV test results [2628,34], access to care and health outcomes [26,32,33], it follows that rapid anti-HCV assays can similarly benefit high-risk populations. Rapid, point-of-care testing for HCV can expedite and assist in the identification of those $\mathrm{HCV}$-infected persons who are unaware of their infection, presenting new opportunities to provide prevention counselling messages and referrals for follow-up.

Anti-HCV tests detect both current and past HCV infections, but cannot distinguish between them. Persons who have positive anti-HCV test results must also be tested with another assay - currently a NAT - to determine the state of infection. NAT is more expensive and labour-intensive than anti-HCV testing. However, the recently-developed HCV core antigen ( $\mathrm{HCV} \mathrm{Ag)} \mathrm{test} \mathrm{has} \mathrm{the} \mathrm{potential} \mathrm{to} \mathrm{be} \mathrm{used} \mathrm{as} \mathrm{a} \mathrm{relatively} \mathrm{less} \mathrm{expensive} \mathrm{reflex} \mathrm{test} \mathrm{for}$ individuals who are anti-HCV-positive and aid in distinguishing resolved from active 
infections. A quantitative antigen assay, the Architect HCV Ag assay (Abbott, Abbott Park, IL, USA), performed on an automated platform, is now commercially available in Europe [35]. Several studies in blood donors have shown the detection of HCV core Ag within the first 2 weeks of acute infection [36]. The advantages of HCV Ag assay are that it is an immunoassay, does not require the same labour-intensive and expensive sample processing, as in molecular assays, and its detection confirms active infection; however, the test has a lower sensitivity when compared to NAT.

The evaluation studies described in this paper have some limitations. The total number of samples tested by the OraSure assay was greater than the number of samples tested by the Chembio and MedMira assays, providing OraSure with more opportunities for evaluation. Investigators of three of the six studies reviewed [19-21] had financial relationships with OraSure. The evaluation of the MedMira assay also was limited in that the platform did not allow for oral fluid testing. In one field setting, the MedMira assay was evaluated without incorporating the CDC algorithm in the analysis of results [22]. The MedMira rapid assay results were compared to results from the screening EIA only and may have resulted in a lower sensitivity than if compared to the CDC algorithm. Lastly, none of the studies included in the review had more than $50 \mathrm{HIV}-\mathrm{HCV}$-coinfected specimens to refine the level of precision required for an acceptable evaluation of such specimens.

\section{Conclusions}

Anti-HCV rapid tests can play a significant role in increasing the proportion of HCVinfected persons who are aware of their infection status, especially among at-risk populations. Further studies are needed to evaluate the performance characteristics of the rapid anti-HCV assay for specimens from HIV-HCV-coinfected persons. Finally, future research should be targeted towards the development of immunoassays for detection of $\mathrm{HCV}$ antigen and NAT in rapid test formats.

\section{References}

1. Armstrong GL, Wasley A, Simard EP, McQuillan GM, Kuhnert WL, Alter MJ. The prevalence of hepatitis C virus infection in the United States, 1999 through 2002. Ann Intern Med. 2006; 144:705-714. [PubMed: 16702586]

2. CDC. Recommendations for prevention and control of hepatitis C virus (HCV) infection and HCVrelated chronic disease. MMWR Recomm Rep. 1998; 47:1-39.

3. Roblin DW, Smith BD, Weinbaum CM, Sabin ME. Hepatitis C virus screening practices and prevalence in a managed care organization, 2000-2007. Am J Manag Care. 2011; 17:548-555. [PubMed: 21851142]

4. Southern WN, Drainoni ML, Smith BD, et al. Hepatitis C testing practices and prevalence in a highrisk urban ambulatory care setting. J Viral Hepat. 2011; 18:474-481. [PubMed: 20497311]

5. Wasley, A., Finelli, L., Bell, BP., Alter, MJ. The knowledge and behavior of HCV-infected persons identified in a national seroprevalence survey, United States, 2001-2004. 12th International Symposium on Viral Hepatitis and Liver Disease; 1-5 July 2006; Paris, France. Poster 445

6. CDC. Viral Hepatitis Surveillance United States, 2009. MMWR. 2011; 58:1-27. [PubMed: 21566560]

7. Amon JJ, Garfein RS, Ahdieh-Grant L, Armstrong GL, et al. Prevalence of hepatitis C virus infection among injection drug users in the United States, 1994-2004. Clin Infect Dis. 2008; 46:1852-1858. [PubMed: 18462109] 
8. Hagan H, Pouget ER, Des Jarlais DC, Lelutiu-Weinberger C. Meta-regression of hepatitis C virus infection in relation to time since onset of illicit drug injection: the influence of time and place. Am J Epidemiol. 2008; 168:1099-1109. [PubMed: 18849303]

9. Edlin BR, Carden MR. Injection drug users: the overlooked core of the hepatitis C epidemic. Clin Infect Dis. 2006; 42:673-676. [PubMed: 16447113]

10. Thorpe LE, Ouellet LJ, Hershow R, et al. Risk of hepatitis C virus infection among young adult injection drug users who share injection equipment. Am J Epidemiol. 2002; 155:645-653. [PubMed: 11914192]

11. Garfein RS, Doherty MC, Monterroso ER, Thomas DL, Nelson KE, Vlahov D. Prevalence and incidence of hepatitis $\mathrm{C}$ virus infection among young adult injection drug users. J Acquir Immune Defic Syndr Hum Retrovirol. 1998; 18(Suppl 1):S11-S19. [PubMed: 9663618]

12. Hahn JA, Page-Shafer K, Lum PJ, Ochoa K, Moss AR. Hepatitis C virus infection and needle exchange use among young injection drug users in San Francisco. Hepatology. 2001; 34:180-187. [PubMed: 11431749]

13. Spradling PR, Richardson JT, Buchacz K, et al. Trends in hepatitis C virus infection among patients in the HIV Outpatient Study, 1996-2007. J Acquir Immune Defic Syndr. 2010; 53:388396. [PubMed: 19738485]

14. Tempalski B, Lieb S, Cleland CM, Cooper H, Brady JE, Friedman SR. HIV prevalence rates among injection drug users in 96 large US metropolitan areas, 1992-2002. J Urban Health. 2009; 86:132-154. [PubMed: 19015995]

15. Kaplan JE, Masur H, Holmes KK. Guidelines for preventing opportunistic infections among HIVinfected persons-2002. Recommendations of the U.S. Public Health Service and the Infectious Diseases Society of America. MMWR Recomm Rep. 2002; 51:1-52.

16. Taylor LE. Delivering care to injection drug users coinfected with HIV and hepatitis $\mathrm{C}$ virus. Clin Infect Dis. 2005; 40(Suppl 5):S355-S361. [PubMed: 15768348]

17. Jewett A, Smith BD, Garfein RS, Cuevas-Mota J, Teshale EH, Weinbaum CM. Field-based performance of three pre-market rapid hepatitis C virus antibody assays in STAHR (Study to Assess Hepatitis C Risk) among young adults who inject drugs in San Diego, CA. J Clin Virol. 2012; 54:213-217. [PubMed: 22560051]

18. Molitor F, Bell RA, Truax SR, Ruiz JD, Sun RK. Predictors of failure to return for HIV test result and counseling by test site type. AIDS Educ Prev. 1999; 11:1-13. [PubMed: 10070585]

19. Drobnik A, Judd C, Banach D, Egger J, Konty K, Rude E. Public health implications of rapid hepatitis $\mathrm{C}$ screening with an oral swab for community-based organizations serving high-risk populations. Am J Public Health. 2011; 101:2151-2155. [PubMed: 21940910]

20. Lee SR, Kardos KW, Schiff E, et al. Evaluation of a new, rapid test for detecting HCV infection, suitable for use with blood or oral fluid. J Virol Methods. 2011; 172:27-31. [PubMed: 21182871]

21. Lee SR, Yearwood GD, Guillon GB, et al. Evaluation of a rapid, point-of-care test device for the diagnosis of hepatitis C infection. J Clin Virol. 2010; 48:15-17. [PubMed: 20362493]

22. Smith BD, Drobeniuc J, Jewett A, et al. Evaluation of three rapid screening assays for detection of antibodies to hepatitis C virus. J Infect Dis. 2011; 204:825-831. [PubMed: 21849279]

23. Smith BD, Teshale E, Jewett A, et al. Performance of premarket rapid hepatitis $\mathrm{C}$ virus antibody assays in 4 national HIV behavioral surveillance system sites. Clin Infect Dis. 2011; 53:780-786. [PubMed: 21921221]

24. Alter MJ, Kuhnert WL, Finelli L. Guidelines for laboratory testing and result reporting of antibody to hepatitis C virus. Centers for Disease Control and Prevention. MMWR Recomm Rep. 2003; 52:1-13.

25. van den Berg CH, Grady BP, Schinkel J, et al. Female sex and IL28B, a synergism for spontaneous viral clearance in hepatitis $\mathrm{C}$ virus $(\mathrm{HCV})$ seroconverters from a community-based cohort. PLoS ONE. 2011; 6:e27555. [PubMed: 22110669]

26. Kendrick SR, Kroc KA, Withum D, Rydman RJ, Branson BM, Weinstein RA. Outcomes of offering rapid point-of-care HIV testing in a sexually transmitted disease clinic. J Acquir Immune Defic Syndr. 2005; 38:142-146. [PubMed: 15671798] 
27. Lubelchek R, Kroc K, Hota B, et al. The role of rapid vs conventional human immunodeficiency virus testing for inpatients: effects on quality of care. Arch Intern Med. 2005; 165:1956-1960. [PubMed: 16186464]

28. Metcalf CA, Douglas JM Jr, Malotte CK, et al. Relative efficacy of prevention counseling with rapid and standard HIV testing: a randomized, controlled trial (RESPECT-2). Sex Transm Dis. 2005; 32:130-138. [PubMed: 15668621]

29. Greub G, Ledergerber D, Battegay M, et al. Clinical progression, survival, and immune recovery during antiretroviral therapy in patients with HIV-1 and hepatitis C virus coinfection: the Swiss HIV Cohort Study. Lancet. 2000; 356:1800-1805. [PubMed: 11117912]

30. Vali B, Jones RB, Sakhdari A, et al. HCV-specific T cells in HCV/HIV co-infection show elevated frequencies of dual Tim-3/PD-1 expression that correlate with liver disease progression. Eur J Immunol. 2010; 40:2493-2505. [PubMed: 20623550]

31. Soriano V, Sulkowski M, Bergin C, et al. Care of patients with chronic hepatitis C and HIV coinfection: recommendations from the HIV-HCV International Panel. AIDS. 2002; 16:813-828. [PubMed: 11919483]

32. Keenan PA, Keenan JM. Rapid hiv testing in urban outreach: a strategy for improving posttest counseling rates. AIDS Educ Prev. 2001; 13:541-550. [PubMed: 11791785]

33. Christopoulos KA, Kaplan B, Dowdy D, et al. Testing and linkage to care outcomes for a clinicianinitiated rapid HIV testing program in an urban emergency department. AIDS Patient Care STDS. 2011; 25:439-444. [PubMed: 21545296]

34. Spielberg F, Branson BM, Goldbaum GM, et al. Choosing HIV counseling and testing strategies for outreach settings: a randomized trial. J Acquir Immune Defic Syndr. 2005; 38:348-355. [PubMed: 15735456]

35. Muerhoff AS, Jiang L, Shah DO, et al. Detection of HCV core antigen in human serum and plasma with an automated chemiluminescent immunoassay. Transfusion. 2002; 42:349-356. [PubMed: 11961241]

36. Hosseini-Moghaddam SM, Iran-Pour E, Rotstein C, et al. Hepatitis C core Ag and its clinical applicability: potential advantages and disadvantages for diagnosis and follow-up? Rev Med Virol. 2012; 22:156-165. [PubMed: 22121001] 


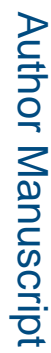

로을

$\frac{\overline{0}}{\frac{0}{\sigma}}$

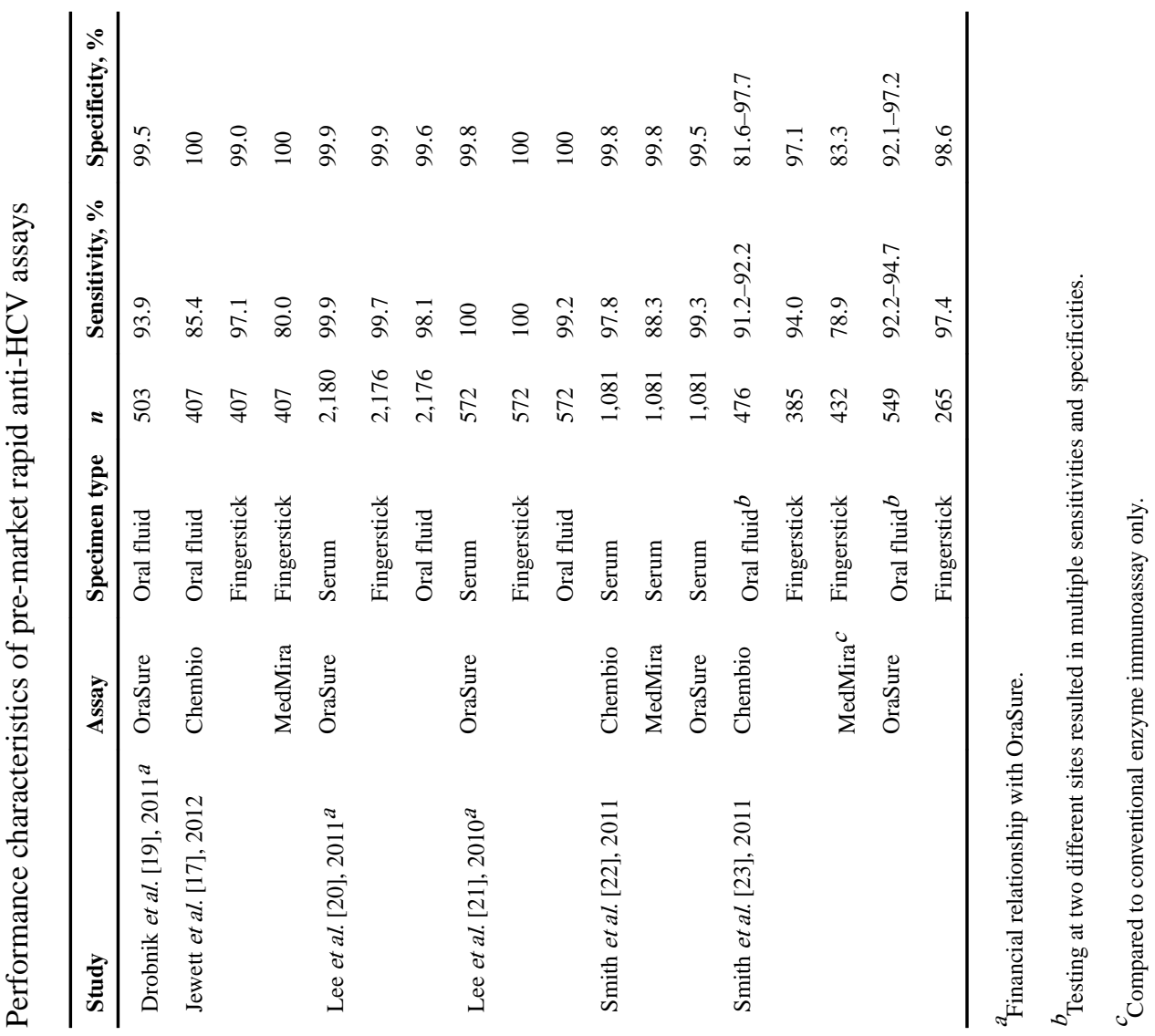

Antivir Ther. Author manuscript; available in PMC 2018 January 31. 